Original article

\title{
Features of anxiety and attention in elementary school students of the Russian North
}

\author{
Olga P. Bartosh, Tatiana P. Bartosh, Marina V. Mychko \\ Scientific Research Center 'Arktika' Far Eastern Branch of the Russian Academy of Sciences
}

Received 18 November 2020, Revised 28 April 2021, Accepted 26 August 2021

(C) 2020, Russian Open Medical Journal

\begin{abstract}
A child's body in the contemporary educational process with innovative programs and electronic devices, along with insufficient motor activity, against the background of low reserve capacity in the North, experiences the psychoemotional stress.

The objective of our study was to investigate the anxiety and attention in elementary school students in the northern cities of Magadan Oblast. The study was conducted on elementary school students ( $9.9 \pm 0.05$ years of age) in the regional center of Magadan and the remote town of Magadan Oblast, Susuman. Group I consisted of 108 Magadan school students, whereas Group II included 82 Susuman school students.

Methods - we used the methodology of multidimensional assessment of childhood anxiety (MACA). To investigate the function of attention, we used the method of proofreading modified by V.N. Amatuni.

Results - the number of anxious children was $42 \%$ in Magadan and $26 \%$ in Susuman. Magadan children were significantly more anxious than their Susuman peers on five of ten scales: in connection with the evaluation by others ( $M \pm S E: p=0.013 ; M e$ [Q1; $Q 3]$ : $p<0.05)$; in their relationships with teachers $(p=0.003 ; p<0.01)$; in terms of their learning success $(p=0.016 ; p<0.05)$; in situations of knowledge testing $(p=0.022 ; p<0.05)$; and they also exhibited an increase in their autonomic reactivity associated with anxiety $(p=0.040 ; p<0.05)$. It was revealed as well that the neurodynamic characteristics of attention were better in the group of Susuman children.

Conclusion - It can be assumed that elementary school students in small remote towns are less at risk of school maladjustment and are more efficient than their peers living in larger cities, where anxiety is higher, which complicates the learning process.
\end{abstract}

Keywords: anxiety, attention, elementary school students, northern cities.

Cite as Bartosh OP, Bartosh TP, Mychko MV. Features of anxiety and attention in elementary school students of the Russian North. Russian Open Medical Journal 2021; 10: e0314.

Correspondence to Olga Bartosh. Address: Group of Psychophysiology, Scientific Research Center 'Arktika' Far Eastern Branch of the Russian Academy of Sciences, K. Marks St., 24, Magadan 685000, Russia. Phone: (+7) 914-863-5514. Email: olga bartosh@inbox.ru.

\section{Introduction}

Environmental conditions, including climatic specificities have a direct impact on human body and its reserve capacity, more so in the northern regions. They may contribute to the onset of pathology, both in adults and in children [1, 2]. A significant increase in educational loads with the introduction of 'presumably innovative' programs of ambiguous quality into the educational process at a contemporary school, along with insufficient physical activity, continuous contact with electronic devices, and nomophobia create a very high level of psychoemotional stress and overwork in both students and teachers $[3,4]$.

A child's body in the process of intense intellectual activity against the background of low reserve capacity experiences a higher stress than a body of an adult, in particular, in children of the North, and higher neural energy costs of the brain [5]. Overstrain in children due to hypokinesia, insufficient maturity of autonomic support systems and mechanisms of their regulation leads to an increase in the number of chronic diseases, various functional disorders, and higher incidence of neuroses [6, 7]. Number of neurotic school students steadily grows $[3,8,9]$, characterized by augmented anxiety, insecurity, emotional instability, and the presence of phobias. We should mention the positive influence of moderate (adequate) anxiety on the development of children, which mobilizes the learning process, promotes self-development, functioning at a more mature level, and better socialization [10]. However, inadequate anxiety is a stable functional component of the emotional sphere: it could negatively affect all spheres of a school student's life and be a risk factor for school maladjustment. Younger school students begin doubting their capabilities and strengths, constant anxiety interferes with their concentration on something, their attention and memory become negatively affected, and they are in a state of muscle tension $[9,11]$. The emerging anxiety disorganizes not just educational activity, it begins distorting the formation of the personality. By adolescence, anxiety is established, and it becomes a persistent component of the personality $[8,9,12]$.

Knowledge related to the patterns of the increased anxiety emergence in children would facilitate providing the corrective assistance in a timely manner, or using preventive measures to form an adequate behavior of elementary school students. Also, within the framework of the psychological correction, the higher mental functions' correction with psychophysiological orientation via the biofeedback method, various social and psychological 
trainings, and art therapy techniques has proven itself quite well [13].

The objective of our study was to investigate the anxiety and function of attention in elementary school students in the northern cities of Magadan Oblast.

\section{Material and methods}

Our study was conducted on elementary school students (grades 3 and 4) of public schools, whose average age was $9.9 \pm 0.05$ years. Almost simultaneously, in March, we initiated our research in the regional center of Magadan and the remote town of Magadan Oblast, Susuman. Group I consisted of 108 Magadan

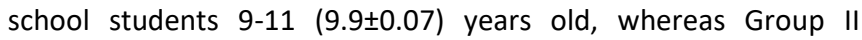
comprised 82 Susuman school students $9.9 \pm 0.08$ years old.

\section{Climatic features of the study sites}

Magadan and Susuman differ in terms of their climatic conditions. Magadan is $626 \mathrm{~km}$ apart from Susuman by the highway, or $385 \mathrm{~km}$ in a straight line. Magadan is characterized by a subarctic climate with maritime features. Winters are long and cold, softened by the Sea of Okhotsk. Summers are short and cool with frequent winds. The climate in Susuman is harsh, humid continental with dry winters and warm summers. In 2019, the population of Magadan was 91,781 people, while town of Susuman had 4,588 residents.

\section{Study of anxiety}

The method of multidimensional assessment of childhood anxiety (MACA) was developed and tested by E.E. Malkova [14]. The methodology is based on the technique originally developed by Phillips [15]. MACA includes 10 parameters to provide a differentiated assessment of anxiety: 1 - general anxiety; 2 - peer anxiety (in relationships with peers); 3 - anxiety in connection with the evaluation by others; 4 - anxiety in relationships with teachers; 5 - anxiety in relationships with parents; 6 - anxiety related to the learning success; 7 - anxiety associated with selfexpression; 8 - test anxiety (associated with knowledge testing); 9 - decrease in mental performance associated with anxiety; 10 - an increase in autonomic reactivity associated with anxiety. Each anxiety parameter scores 1 to 10 . If a parameter is poorly expressed, it is scored 1-2 points; $4-5$ points are assigned if a parameter is clearly expressed; 7-10 points stand for strongly expressed anxiety indicator. The total cumulative score on all 10 scales of the questionnaire (maximum of 100 points) is expressed by the Integral Anxiety Index of (IAI).

\section{Study of attention}

To study the function of attention, we used the method of proofreading modified by VN Amatuni [3]. The method was developed and tested by L.I. Wasserman and M.V. Katysheva at the Laboratory of Psychology of the Bekhterev National Medical Research Center for Psychiatry and Neurology. A total of 800 numbers (400 in each of upper, lower, left and right halves of the table, divided by the perpendicular lines into four equal quadrants). For the convenience of the study subject, the numbers were enlarged (numbers 6 and 9), but their sequence was not changed compared to the original table design. The results of the experiment represent the following parameters: time of proofreading the $1^{\text {st }}$ horizontal half of the table (t 1$)$; total time of performing the task $(T)$; time of proofreading the $2^{\text {nd }}$ horizontal half of the table $\left(t_{2}=T-t_{1}\right)$; the index of fatigue (IF) according to the formula IF $=t_{1} / t_{2}$. The smaller the IF value (the more IF deviates from 1), the greater the likelihood of increased fatigue, reduced active attention and declined mental performance of the study subject. Whenever IF is higher than 1 , or close to 1 , we can state normal or increased mental performance. Factors of functional attention asymmetry (AA) were also analyzed. With this goal in mind, the amounts of erroneously crossed out or missed numbers in the right and left halves of the table were counted. The AA coefficient was calculated using the formula $A A C=R H / L H$, where $\mathrm{RH}$ is the number of mistakes in the right half of the table, and $\mathrm{LH}$ is the number of mistakes in the left half of the table. Concentration of Attention (CA) was calculated by the formula CA $=$ number of viewed lines $/$ number of errors.

\section{Statistical analysis}

The collected data were processed using the Statistica 6.0 software package. Our data are presented as the arithmetic mean and its error $(\mathrm{M} \pm \mathrm{SE})$; median $(\mathrm{Me})$ and interquartile range in the form of the $25^{\text {th }}$ and $75^{\text {th }}$ percentiles of Me (Q1; Q3). The distributions of measured variables were tested for normality using the Shapiro-Wilk test. The statistical significance of the differences among the groups was determined using the Student's $\mathrm{t}$-test for independent samples with a normal distribution.

The study design matched the requirements of the Declaration of Helsinki. The study protocol was approved by the Ethics Committee on Biomedical Research at the Northeastern Scientific Center, Far Eastern Branch of the Russian Academy of Sciences (Protocol No.1 of March 29, 2019).

\section{Results}

When comparing the groups of elementary school students living in Magadan versus residing in Susuman, we could see that Magadan children had higher anxiety on five scales of ten: for anxiety in connection with the evaluation by others, $p=0.013$ (for group means) and $p<0.05$ (for group medians); for anxiety in relationships with teachers, $p=0.003$ and $p<0.01$; for anxiety related to the learning success, $p=0.016$ and $p<0.05$; for test anxiety, $p=0.022$ and $p<0.05$; for increase in autonomic reactivity associated with anxiety, $\mathrm{p}=0.040$ and $\mathrm{p}<0.05$ (Table 1 ). Susuman children had better neurodynamic indicators of attention.

Magadan elementary school students were more anxious about the assessments given by others (scale 3). As a rule, such type of anxiety arises in significant situations and is manifested by the fear of not meeting the expectations of the surrounding significant adult people (teachers, parents). Excessive claims of parents to the capabilities of their child lead to the child's dissatisfaction of such basic needs as the need for love, which also provokes the development of anxious reactions. Also, Magadan children were more likely to exhibit anxiety in relationships with teachers (scale 4), which could negatively affect their learning success in general. Such school students tend to have a rather high motivation for schooling; hence they are sensitive to injustice or tactlessness on the part of their teacher. School grades are perceived by a child as an additional source of excitement and fear. Scales 6 and 8 reflect the anxiety associated with schooling and, once again, such anxiety was higher among Magadan elementary school students. Performance anxiety (scale 6) 
prevents school students from developing their needs of highquality performance. In such children, the motivation for avoiding failure prevails over the motivation for achieving success. Scale 8, reflecting the anxiety arising in situations of knowledge testing, was also significantly higher among elementary school students in Magadan. Fear of publicly displaying one's knowledge provokes feelings of anxiety and self-doubt. The average group anxiety indicator (Me) on scale 10 was not very high, but some children with high values of this indicator were noted. These elementary school students had an augmented autonomic reactivity caused by anxiety, and had a high likelihood of developing a psychosomatic response to an alarming environmental factor. This pattern can manifest itself in frequent colds, gastrointestinal disorders and disorders of the cardiovascular system functioning, along with headaches and allergic reactions after, or even immediately before, stressful situations [14].

A detailed examination of our data showed that the Magadan sample comprised $42 \%(n=45)$ of highly anxious children, of which $22 \%$ were boys and $20 \%$ were girls. In the Susuman sample, $26 \%$ $(n=21)$ were children with high anxiety, of which $11 \%$ were boys and $15 \%$ were girls.

The results of our attention function study in elementary school students of Magadan group versus Susuman group are presented in Table 2.

Our data suggested that three parameters associated with time required for performing certain task $-t_{1}, t_{2}$ and $T-$ were higher in Magadan children, but only $t_{2}$ exhibited the statistical significance of difference among the groups. This finding implies a slower pace of performing the task. Also, Magadan children had a higher number of errors when completing the test in the left and right halves of the table ( $p=0.012$ and $p<0.05$, respectively). The IF values of approximately 1 indicated normal mental performance in both groups. The AAC was lower in Susuman children versus Magadan group (1.21 vs. 1.95; $\mathrm{p}=0.029, \mathrm{p}<0.05)$; whereas CA was higher in Susuman school students versus Magadan children (4.01 vs $2.87 ; \mathrm{p}=0.096)$, which suggested a better balance of intrahemispheric, interhemispheric, and cortical-subcortical interrelationships [16].

\section{Discussion}

However, as our research has shown, in a larger city, the number of anxious children among elementary school students is higher and the level of anxiety is also higher than in a small remote town. As V.M. Polyakov pointed out in his article, "... the additional loads of the urban environment are accompanied by a high prevalence in children of emotional disorders associated with fatigue, increased anxiety, sleep disorders, and excessive aggressiveness" [17].

Thus, our results are consistent with the data of researchers who suggested that about a third of school students had elevated or very high level of personal anxiety caused by school-related situations [12]. Moreover, anxiety can be associated with fear of knowledge testing, evaluative situations, and self-expression, as well as low physiological resistance to stress $[11,18]$. This can also be associated with overinflated expectations on the part of the parents, along with individual styles of the teachers $[8 ; 11]$. Probably, the environmental pressure of living in a larger city, the conditions of competition among students and schools, contemporary interactive teaching technologies, and higher demands on the part of the teachers increase the stress of students, leading to their higher anxiety.

Table 1. Indicators of childhood anxiety in elementary school students of Magadan and Susuman

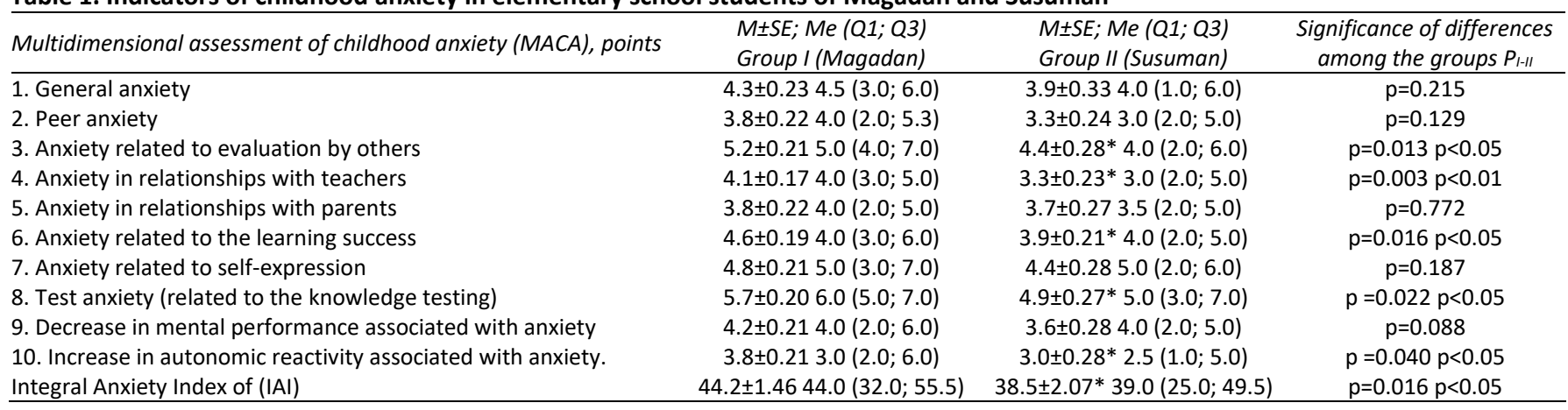

* statistically significant differences between the school students of Magadan and Susuman.

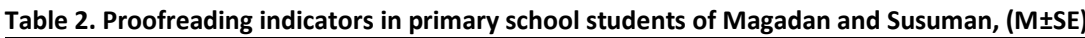

\begin{tabular}{|c|c|c|c|}
\hline Indicator & Magadan $n=108$ & Susuman $\mathrm{n}=82$ & PMagadan-Susuman Student's t-criterion \\
\hline Time of proofreading the $1^{\text {st }}$ horizontal half of the table $\left(t_{1}\right)$ & $2.63 \pm 0.09$ & $2.49 \pm 0.09$ & $p=0.202$ \\
\hline Total time of performing the task $(\mathrm{T})$ & $5.27 \pm 0.16$ & $4.91 \pm 0.15$ & $p=0.059$ \\
\hline Time of proofreading the $2^{\text {nd }}$ horizontal half of the table $\left(t_{2}=T-t_{1}\right)$ & $2.62 \pm 0.08$ & $2.43 \pm 0.08^{*}$ & $p=0.050 p<0.05$ \\
\hline Index of fatigue (IF) & $1.03 \pm 0.03$ & $1.03 \pm 0.04$ & $p=0.857$ \\
\hline Number of mistakes in the right half of the table $(\mathrm{RH})$ & $8.10 \pm 0.92$ & $5.74 \pm 0.65^{*}$ & $p=0.012 p<0.05$ \\
\hline Number of mistakes in the left half of the table (LH) & $5.40 \pm 0.64$ & $4.86 \pm 0.68$ & $p=0.505$ \\
\hline Attention asymmetry coefficient (AAC) & $1.95 \pm 0.36$ & $1.21 \pm 0.21 *$ & $p=0.029 p<0.05$ \\
\hline Concentration of attention (CA) & $2.87 \pm 0.44$ & $4.01 \pm 0.61$ & $p=0.096$ \\
\hline
\end{tabular}

* statistically significant differences between the school students of Magadan and Susuman. 
The presented results support the findings of other authors, suggesting that high anxiety negatively affects the function of attention and can be a risk factor for school maladjustment $[9,11$, 13]. It can be assumed that elementary school students in the town of Susuman are distinguished by a higher (than in Magadan school students) harmonization of their left and right hemispheres' functioning. The latter are responsible for the control and accuracy of the task completion, better performance, and, in general, better regulation of the activity of the neurodynamic attention characteristics. However, our hypothesis needs testing in further in-depth research. Also, it is not definite that the above-listed tendencies would persist in adolescence.

The physiological, psychological and behavioral aspects of the functional state of an individual are positively influenced by various types of prevention, sports training and timely corrective assistance, especially in people with an increased level of anxiety $[6,13,19]$

Taking into account the above reasoning, we can conclude that it is important for the present-day schools to preserve their students' health rather than concentrate solely on catering to their learning needs. Hence, it is necessary to continuously search for effective ways of managing the educational process, especially in the era of the global digitalization, and to carry out appropriate corrective measures that take into account the intensity and volume of the academic load and the individual characteristics of elementary school students.

\section{Conclusion}

Our research has shown that elementary school students in Magadan are more anxious than children in Susuman on five of ten scales. In the larger city of Magadan, the number of anxious children among elementary school students was higher (42\%) than in the small remote town of Susuman (26\%). Taking into account lower school anxiety in Susuman children and their better attention, it can be assumed that elementary school students in small remote towns (such as Susuman) are less susceptible to the risk of school maladjustment, and are more efficient than their peers living in larger cities (such as Magadan), where anxiety is higher, which complicates the processes of learning, socialization and interpersonal communication.

\section{Ethical approval}

The study was carried out in accordance with the principles of the Declaration of Helsinki. The study protocol was approved by the Ethics Committee on Biomedical Research at the Northeastern Scientific Center, Far Eastern Branch of the Russian Academy of Sciences (Protocol No.1 of March 29, 2019). Parents of participating students were informed about the objectives of the research. Written informed consent forms were signed prior to conducting the research.

\section{Conflict of interest}

The authors declare no apparent or potential conflicts of interest related to the publication of this article.

\section{References}

1. Hasnulin VI, Hasnulin PV. Modern concepts of the mechanisms forming northern stress in humans in high latitudes. Human Ecology 2012; (1): 3-11. Russian. https://www.elibrary.ru/item.asp?id=17474846.
2. Young TK, Mäkinen TM. The health of arctic populations: Does cold matter? Am J Hum Biol 2010; 22(1): 129-133. https://doi.org/10.1002/ajhb.20968.

3. Ozhogova EG, Namsing EV. Dynamics and factors of anxiety from schoolchildrenю Problems of modern pedagogical education 2018; (614): 314-317. Russian. https://elibrary.ru/item.asp?id=36809712.

4. Hoge E, Bickham D, Cantor J. Digital media, anxiety, and depression in children. Pediatrics 2017; 140(Suppl 2): S76-S80. https://doi.org/10.1542/peds.2016-1758G.

5. Gribanov AV, Nekhoroshkova AN, Deputy IS, Pankov MN Kozhevnikova IS. Cerebral energy metabolism in children with high level of anxiety. Yakut Medical Journal 2019; (4(68)): 86-88. Russian. https://doi.org/10.25789/YMJ.2019.68.24.

6. Krivolapchuk IA, Gerasimova AA, Myshiakov VV, Chicherin VP. The effect of anaerobic glycolytic performance on the functional status and cognitive efficiency in primary schoolchildren. Human. Sport. Medicine 2019. 19(S2): 29-36. Russian. https://doi.org/10.14529/hsm19s204.

7. Cummings CM, Caporino NE, Kendall PC. Comorbidity of anxiety and depression in children and adolescents: 20 years after. Psychol Bull 2014; 140(3): 816-845. https://doi.org/10.1037/a0034733.

8. Purgina AA, Onufrieva VV. Correction of anxiety in elementary school students. Molodoy uchoniy 2015; (7(87)):700-702. Russian. https://www.elibrary.ru/item.asp?id=23287353.

9. Prikhozhan AM. The Psychology of Anxiety: Preschool and School Age. 2nd Ed. St. Petersburg, Russia: Piter. 2009; 192 p. Russian. https://search.rsl.ru/ru/record/01007494654.

10. Barlow DH, ed. Anxiety and its Disorders: The Nature and Treatment of Anxiety and Panic. New York: Guilford Press. 2002; 704 p. https://www.guilford.com/books/Anxiety-and-Its-Disorders/DavidBarlow/9781593850289.

11. Gurov VA, Kazin EM, Belonogova EV. Dynamics of some parameters psychophysiological development of younger schoolboys interrelating on the level and structures of anxiety. Journal of Health and Life Sciences 2014; (2): 11-16. Russian. https://www.elibrary.ru/item.asp?id=22917404.

12. Demidova IG. Features of personal anxiety in early teens. Humanitarian Scientific Bulletin 2020; (2): 76-81. Russian. https://doi.org/10.5281/zenodo.3744297.

13. Bartosh OP, Bartosh TP. Corrective measures for the prevention of high anxiety and attention disorders in junior schoolchildren. Profilakticheskaya Meditsina 2018; 21(2-1): 34-39. Russian. https://doi.org/10.17116/profmed201821234-39.

14. Vasserman LI, Malkova EE. Psychodiagnostic technique for multidimensional assessment of childhood anxiety. A guide for doctors and psychologists. St. Petersburg, Russia: V.M. Bekhterev Research Psychoneurological Institute. 2007; 35 p. Russian. https://www.studmed.ru/view/vasserman-li-malkova-eepsihodiagnosticheskaya-metodika-dlya-mnogomernoy-ocenki-detskoytrevozhnosti_75d2707a0ff.html.

15. Phillips BN. School Stress and Anxiety: Theory, Research, and intervention. New York: Human Science Press. 1978; 165 p.

16. Vasserman LI, Dorofeeva SA, Meerson YaA. Methods of Neuropsychological Diagnostics. Practical guide. St. Petersburg, Russia Stroilespechat Publisers. 1997; 360 p. Russian. https://clinicpsy.ucoz.ru/Library/vasserman_I.imetody nejropsikhologicheskoj diagno.pdf.

17. Polyakov VM. Development of Higher Mental Processes in Urban and Rural Children. Cultural-Historical Psychology 2008; (1): 9-16. Russian. https://www.elibrary.ru/item.asp?id=11750652.

18. Gorokhova ZN, Matveeva NP, Nikolaev EV, Kuzmina Al, Kornilova AG. School anxiety of students at rural and urban educational institutions of the Republic of Sakha (Yakutia). Yakut Medical Journal 2009; (1(25)): 52-54. Russian. https://www.elibrary.ru/item.asp?id=25010641.

19. Hoare E, Milton K, Foster C, Allender S. The associations between sedentary behaviour and mental health among adolescents: A 
systematic review. Int J Behav Nutr Phys Act 2016; 13(1): 108. https://doi.org/10.1186/s12966-016-0432-4.

\section{Authors:}

Olga P. Bartosh - PhD, Senior Research Scientist, Scientific Research Center 'Arktika' Far Eastern Branch of the Russian Academy of Sciences, Magadan, Russia. http://orcid.org/0000-0003-0211-1188.

Tatiana P. Bartosh - PhD, Principal Research Scientist, Scientific Research Center 'Arktika' Far Eastern Branch of the Russian Academy of Sciences,

Magadan, Russia. http://orcid.org/0000-0003-4993-5969.

Marina V. Mychko - Junior Research Scientist, Scientific Research Center

'Arktika' Far Eastern Branch of the Russian Academy of Sciences, Magadan, Russia. http://orcid.org/0000-0002-0288-6154. 